\title{
Efficacy of Topical Vibratory Stimulation for Reducing Pain during Trigger Point Injection to the Gastrocnemius: A Randomized Controlled Trial
}

\author{
Sang-Hyun Kimª, M.D., PH.D.; Young-Eun Moon ${ }^{b}$, M.D., PH.D. \\ a. Department of Physical Medicine and Rehabilitation, College of Medicine, Soonchunhyang University Hospital, \\ Bucheon; b. Department of Anesthesiology and Pain Medicine (Moon), Catholic University Seoul St. Mary's hospital
}

\section{Introduction}

Myofascial pain syndrome (MPS) is a common source of local musculoskeletal pain caused by myofascial trigger points (MTrP), which are characterized by hypersensitive, palpable taut bands of muscle that are painful to palpation and cause referred pain. Treatment of MPS includes interruption of the pain cycle by inactivating the MTrP using a trigger point injection (TPI), considerable pain can be induced during the procedure because TPI pain derives from multiple sources, including skin puncture, muscle insertion, withdrawal and reinsertion, and infiltration of the injectant.

Recently, topical vibratory stimulation has been successfully reduce pain associated with several minor invasive medical procedures. The purpose of this study was to determine whether topical vibratory stimulation affects the pain experienced during TPI to the gastrocnemius.

\section{Methods}

Total 60 participants were randomly assigned to the vibration or control group. Each participant was instructed in the use the 100mm VAS and five-point Likert scale by Researcher 1 (R1). The most painful MTrP site in the medial belly of the gastrocnemius and the site designated for application of the topical vibration in the medial popliteal fossa were marked using an indelible pen. The distance between these points was measured by R2.

R1 and R2 then left the intervention room, and R3 entered and prepared to apply the vibrator. The vibrator was turned on for the vibration group, at a frequency of $100 \mathrm{~Hz}$ and intensity of 130 microns. In the control group, the vibrator was applied in the turned-off state (touching the medial popliteal fossa). Next, R2 entered the room with earplugs to mask the noise from the vibrator and mini-vibrators attached to both volar forearms to offset any vibration that might be felt through the participant's body (fig 1). R3 swabbed the MTrP site using alcohol gauze and applied the assigned vibrator (on or off) to the popliteal fossa. After 3-5 seconds, R2 performed TPI with $0.5 \%$ lidocaine using a 25 -gauge, 2-inch-long needle. Immediately after TPI, the participant was asked to fill out the self-administered scales regarding pain during TPI (100-mm VAS were the primary outcome measure with respect to pain during TPI of the medial gastrocnemius, and a fivepoint Likert scale ( 1 = strongly agree, $2=$ agree, $3=$ undecided, 4 = disagree, 5 = strongly disagree) was used to answer two questions: "Are you satisfied with the topical vibratory stimulation used during the TPI?" and "Will you use the topical vibratory stimulation again if the TPI is repeated in the future?"), and to seal them in an envelope. Finally, the participant submitted the documents to R1, who was waiting outside the room. R1, R2 and $\mathrm{R} 3$ were blinded to the parts of the study process that did not include them, and they did not communicate among themselves about the study processes.

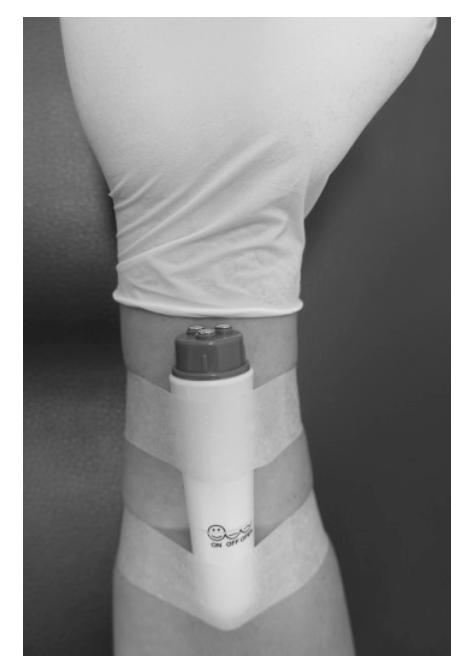

Figure 1. Mini-vibrators attached to the volar forearms of the researcher who performed trigger point injection (TPI) to offset vibration that might be felt through the participant's body.

Results

There were no significant differences between the two groups in demographic or clinical characteristics (table 1). The VAS scores for pain during TPI to the medial gastrocnemius, the primary outcome, were $30.30(95 \% \mathrm{Cl}: 22.65-39.26)$ for the vibration group and 47.58 (95\% Cl: $38.80-56.52)$ for the control group. The pain intensity was significantly lower in the vibration than in the control group ( $F=7.74, P<0.01$, Cohen's $d=0.74$; fig 2). The mean difference in VAS scores between the two groups was $17.27(95 \% \mathrm{Cl}: 5.24-29.30)$. With respect to secondary outcomes, participant satisfaction was significantly higher in the vibration than in the control group. Among the vibration group, $43.3 \%$ of subjects strongly agreed or agreed with the question, "Are you satisfied with the topical vibratory stimulation used during TPI?"; in contrast, only $20.0 \%$ of the control group did so (fig 3). Furthermore, $53.3 \%$ of the vibration group and $26.7 \%$ of the control group strongly agreed or agreed with the question, "Will you use the topical vibratory stimulation again if the TPI is repeated in the future?" None of the participants developed swelling or hematomas at the site of TPI, and there were no reported side effects of the topical vibratory stimulation.

\section{Conclusion}

The results of this study show that topical vibratory stimulation may effectively reduce pain during TPI to the medial gastrocnemius. This study is the first trial examining pain reduction during $\mathrm{TPI}$.

Table 1. The baseline characteristics of the participants

\begin{tabular}{|r|c|c|c|}
\hline & Vibration ( $\mathrm{n}=30)$ & Control $(\mathrm{n}=30)$ & $\mathrm{P}$ \\
\hline Age (y) & $53.0 \pm 11.9$ & $55.3 \pm 14.1$ & .50 \\
\hline Sex (M/F) & $12 / 18$ & $9 / 21$ & .42 \\
\hline $\mathrm{BMI}\left(\mathrm{kg} / \mathrm{m}^{2}\right)$ & $23.4 \pm 2.5$ & $23.5 \pm 2.3$ & .94 \\
\hline $\begin{array}{r}\text { Distance between the } \\
\text { head of vibrator and } \\
\text { TPl site (cm) }\end{array}$ & $9.7 \pm 0.9$ & $9.6 \pm 1.1$ & .55 \\
\hline $\begin{array}{r}\text { Level of anxiety about } \\
\text { the TPI, median }\end{array}$ & $3(2-4)$ & $4(2-5)$ & .46 \\
(interquartile range) & & $53.6 \pm 15.4$ & .52 \\
\hline $\begin{array}{r}\text { 100mm-VAS score of } \\
\text { the myofascial pain }\end{array}$ & $51.2 \pm 13.3$ & & \\
$\begin{array}{r}\text { syndrome of } \\
\text { gastrocnemius }\end{array}$ & & & \\
\hline
\end{tabular}

Figure 2. VAS for pain during TPI. the plots indicate margin of the box margin of the box plot) and upper bound of the $95 \%$ confidence interva (upper whisker). ANCOVA was performed, with age, sex, body mass index, anxiety, and the AAS of MPS of the * $P<0.01$.
A B

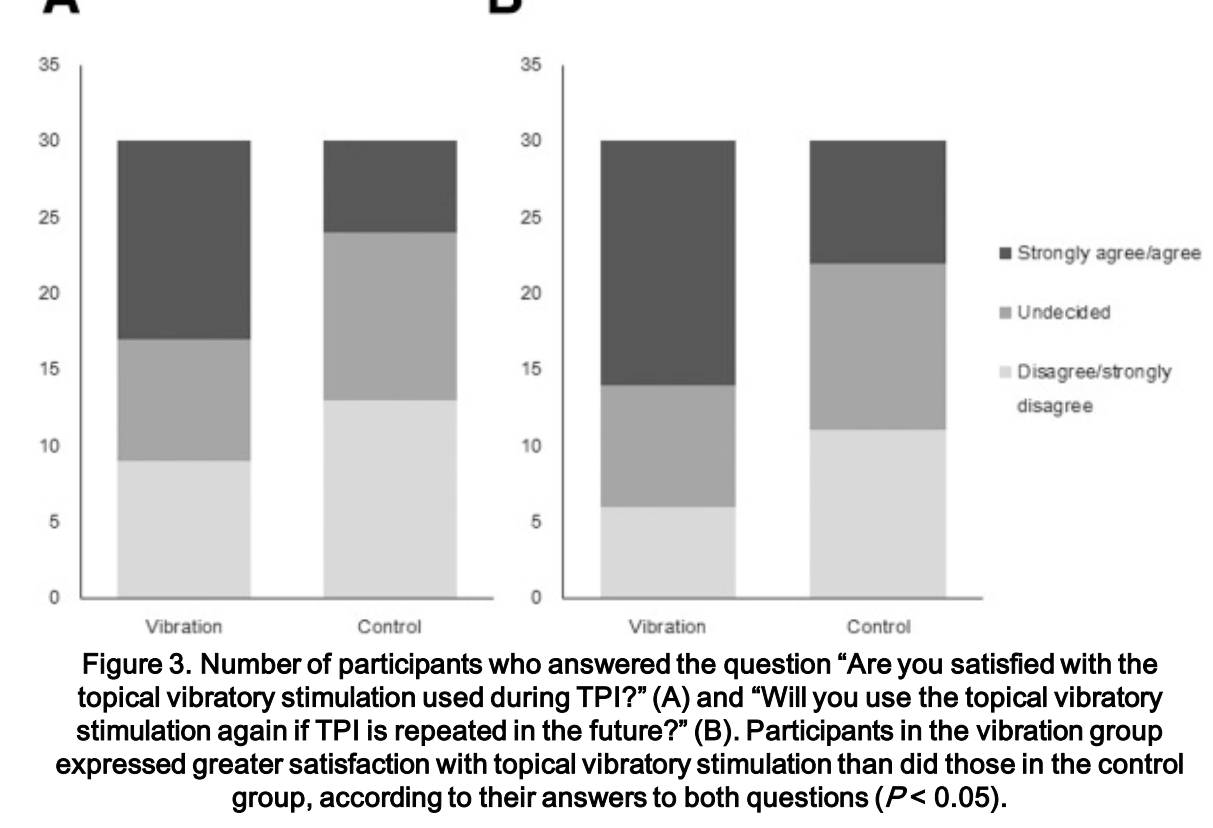

